\title{
Pattern reversal visual evoked potentials in Japanese patients with multiple sclerosis
}

\author{
H SHIBASAKI, ${ }^{*}$ Y KUROIWA ${ }^{\dagger}$ \\ From the Department of Internal Medicine, Saga Medical School, Saga* and Department of Neurology, \\ Neurological Institute, Faculty of Medicine, Kyushu University, Fukuoka, $\dagger$ Japan
}

\begin{abstract}
SUMMARY Forty-seven Japanese patients with multiple sclerosis, 29 probable (clinically definite) and 18 possible, were studied by black-and-white checkerboard pattern reversal visual evoked potential and were compared with a control group of 20 healthy young adults. The major positive peak $(\mathrm{P} \overline{100})$ was found to be abnormal in $70 \%$ of all cases, $90 \%$ of probable cases and $39 \%$ of possible cases. $\mathrm{P} \overline{100}$ was delayed in $38 \%$ of all cases and was absent in $23 \%$ of all cases. None of the eyes showing a flat pattern response was in the acute stage of optic neuritis. The percentage of cases with no response ( $23 \%$ of all cases) was greater than any of the previously reported series from Western countries, substantiating the previously reported clinical features of oriental multiple sclerosis. The pattern response was absent only when testing eyes with severe visual impairment, whereas delayed latency of $\mathrm{P} \overline{100}$ was seen regardless of the severity of visual impairment, suggesting the usefulness of $\mathrm{P} \overline{100}$ latency for detecting subclinical optic nerve lesions.
\end{abstract}

In 1972 Halliday et al' reported a delayed latency of the checkerboard pattern reversal visual evoked potential (VEP) in the affected eye of patients with optic neuritis even after visual acuity had returned to normal. Since then many investigators have confirmed the usefulness of pattern reversal VEP for detecting subclinical optic nerve lesions in optic neuritis and multiple sclerosis. ${ }^{23} \mathrm{~A}$ delayed pattern response has been regarded as highly characteristic of demyelinating diseases although it may not be specific. ${ }^{45}$ The amplitude of the pattern response was found to be correlated with the visual acuity at the time of recording and to recover in parallel with the improvement of visual acuity, while the latency did not correlate with the visual acuity. ${ }^{\circ}$

Oriental multiple sclerosis patients have been claimed to show acute and severe optic nerve involvement more frequently than Caucasian patients probably owing to the more common occurrence of axonal involvement in the former. ${ }^{7-15}$ The present study, therefore, was aimed at investigating whether Japanese multiple sclerosis patients show different features of pattern response abnormalities from Caucasians. This is the first report of pattern reversal VEP in oriental patients with multiple sclerosis.

Address for reprint requests: Hiroshi Shibasaki. M.D.. Department of Internal Medicine. Saga Medical School, Nabeshima, Saga 84()-(1)1. Japan.

Received 10 July 1982.

Accepted 9 August 1982

\section{Subjects and methods}

Subjects for the present study were 49 consecutive Japanese patients with multiple sclerosis seen at Kyushu University Hospital from July 1979 to June 1981, 22 males and 27 females. Overall 58 recordings of pattern reversal VEP were made in these patients. Their age at the time of last recording ranged from 12 to 64 years, mean age 39 years (SD $=12$ years). They consisted of 31 patients with "probable (clinically definite)" multiple sclerosis and 18 patients with "possible" multiple sclerosis according to the diagnostic criteria of the multiple sclerosis Research Committee of Japan. ${ }^{9}$ Duration of the illness from the onset to the time of last recording was 1 month to 30 years, mean 7 years $(\mathrm{SD}=7$ years $)$.

Corrected visual acuity of each eye was tested just preceding VEP recording, and visual impairment of each eye was graded by the Minimum Scoring System of Multiple Sclerosis Disability proposed by the authors. '2 The visual impairment of each eye was categorised into five grades based on the corrected visual acuity; $0 \cdot$ none $(1 \cdot 0)$ or above), 1 slight $(0 \cdot 5$ to $0 \cdot 9), 2$ moderate $(0 \cdot 1$ to $0 \cdot 4), 3$ severe $(0.08$ or less $)$, and 4 completely blind. Twenty healthy young adults, six males and 14 females, aged 18 to 33 years, served as normal controls. Corrected visual acuity was normal in all subjects.

The subject was seated in an arm-chair in a dark room. Pattern reversal VEP was recorded by stimulating each eye separately while the other eye was masked by a white bandage. Visual acuity was corrected by spectacles when necessary. Following Halliday's method,' the slide of a black-and-white checkerboard pattern was projected via a rotatable mirror onto the back of a translucent screen. 
An electromechanical transducer enabled the mirror to be turned through a small angle, causing side-to-side movements of the pattern on the screen every $550 \mathrm{~ms}$. The movement of the mirror took about $15 \mathrm{~ms}$ to complete. The repetitive movements through one square were used to produce an appearance of pattern reversal. The subject sat $80 \mathrm{~cm}$ in front of the screen, the whole stimulating field subtending $32^{\circ}$ at the eye. The individual black-and-white squares subtended 45 minutes. The subject was instructed to fixate on a small red spot in the centre of the screen throughout the runs. A subject who could not see the spot was requested to keep looking straight ahead.

Six recording electrodes were placed on the occipital scalp; $5 \mathrm{~cm}$ and $2.5 \mathrm{~cm}$ above the inion $\left(0 z^{\prime}\right.$ and $0 z$, respectively), $5 \mathrm{~cm}$ and $10 \mathrm{~cm}$ lateral to the $0 z^{\prime}$ electrode on a line joining $0 z^{\prime}$ to the external auditory meatus on each side. A reference electrode was placed at $\mathrm{Fz}$ (International $10-20$ system). Electrode impedance was kept below $5 \mathrm{k} \Omega$. Time constant used was $0.3 \mathrm{~s}$, and the high frequency cut-off of the amplifier was $10 \%$ down at $2,000 \mathrm{~Hz}$. EEGs were averaged by San-ei Signal Processor 7T08 time-locked to the onset of mirror movement. Analysis time was $280 \mathrm{~ms}$ with an ordinate period of $0 \cdot 28 \mathrm{~ms} .100$ to 200 samples were averaged for one session and at least two runs were done for each eye. Measurement of the peak latency was carried out by computer cursoring. Data were plotted on an $\mathrm{X}-\mathrm{Y}$ recorder. With respect to the peak latency of the response and its right-left differences, any value exceeding three standard deviations of the mean value of normal controls was judged abnormal.

\section{Results}

In normal subjects, the major positive peak (PI00) was identified in all trials, being maximal at $0 z^{\prime}$ or $0 z$ electrode. Its mean peak latency was $92.5 \mathrm{~ms}$ (table 1). Preceding $P \overline{100}$, a positive peak was identified at a mean peak latency of $49.9 \mathrm{~ms}(\mathrm{P} \overline{50})$ in $75 \%$ of eyes, and a negative peak was recorded at a mean peak latency of $67.8 \mathrm{~ms}(\mathrm{~N} \overline{70})$ in $95 \%$ of eyes (table 1$)$. Following P $\overline{00}$, a negative peak was recorded at a mean peak latency of $136.0 \mathrm{~ms}(\mathrm{~N} \overline{45})$ in $90 \%$ of eyes. The right-left differences of these peak latencies were very small (table 1 ).

Two patients with probable multiple sclerosis were unable to concentrate during recording session owing

Table 1 Peak latencies and their right $(R)$-left $(L)$ differences of pattern reversal VEP in normal subjects ( 20 subjects, 40 eyes), measured at $0 z^{\prime}$ electrode

\begin{tabular}{llllc}
\hline & $P 5 \overline{0}$ & $N \overline{70}$ & $P \overline{00}$ & $N \overline{45}$ \\
\hline Peak latency & & & & \\
n & 30 & 38 & 40 & 36 \\
mean (ms) & 49.9 & 67.8 & 92.5 & 136.0 \\
SD (ms) & 3.33 & 4.04 & 4.44 & 12.11 \\
R-L difference of & & & & \\
peak latency & & & & \\
n & 15 & 19 & 20 & 18 \\
mean (ms) & 0.2 & 0.7 & -1.4 & -4.3 \\
SD (ms) & 2.00 & 2.28 & 1.86 & 7.67 \\
\hline
\end{tabular}

Table 2 Abnormalities of the major positive component $(P \overline{100})$ of pattern reversal VEP in multiple sclerosis patients (number of cases)

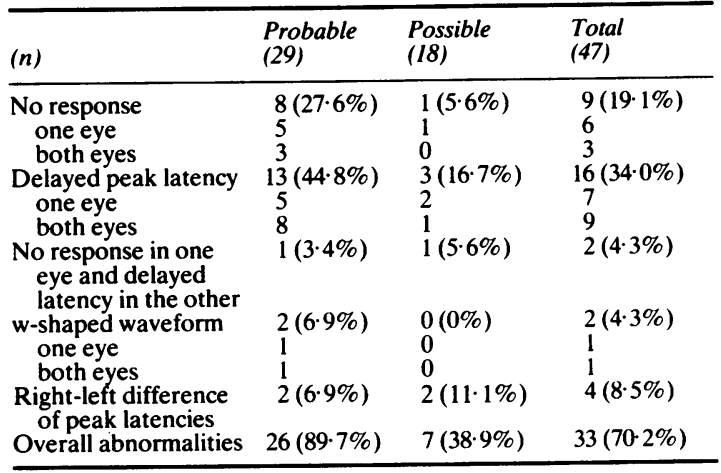

to mental impairment. Among 47 cases who could co-operate, $\mathrm{P} \overline{100}$ was judged abnormal in 33 cases (70\%). Among 29 cases with probable (clinically definite) multiple sclerosis, 26 cases $(90 \%)$ showed some abnormalities in the $\mathrm{P} \overline{100}$ component in comparison with seven among 18 patients with possible multiple sclerosis (39\%) (table 2$)$. The most

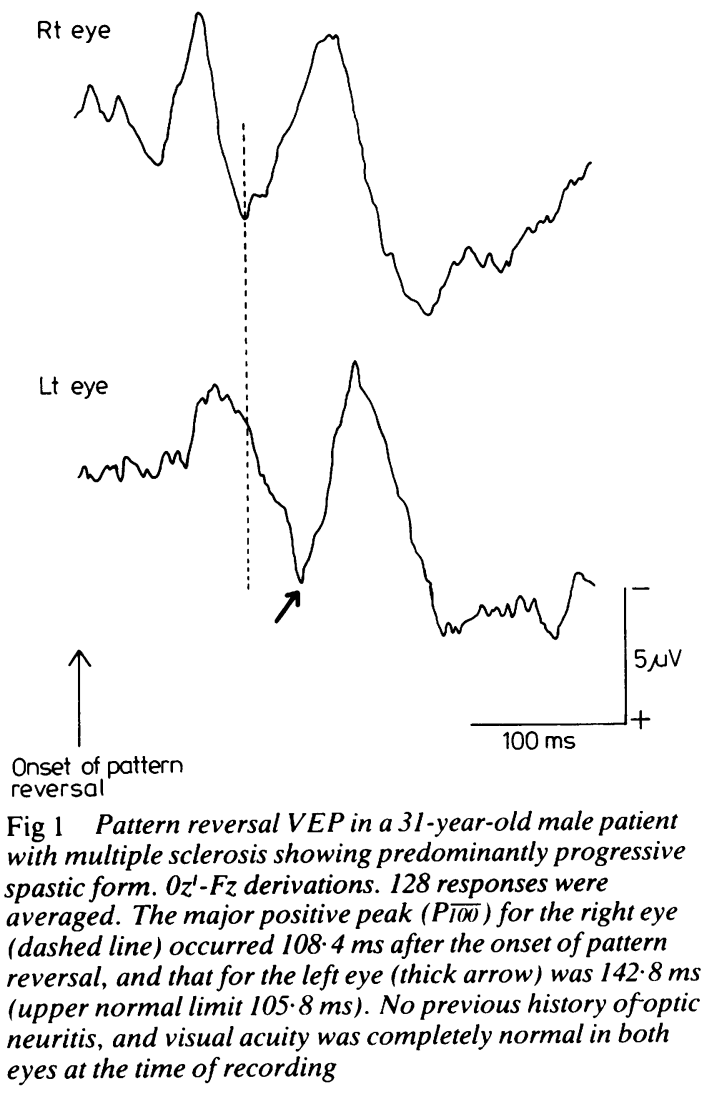


frequent abnormality was the delayed peak latency which was observed in 18 cases (38\% of all cases) (fig 1). In cases showing delayed peak latency of PI(0), all other recognisable components were also delayed. $\mathrm{P} \overline{\mathbf{1 0 0}}$ was absent either in one eye or in both eyes in 11 cases (23\% of all cases). In cases in whom P $\overline{100}$ was not detectable, no other components were identified, either. Right-left difference of P $\overline{(00}$ peak latencies was a single abnormality in four cases $(8.5 \%$ of all cases). Among 29 cases with probable multiple sclerosis, $\mathrm{P} \overline{(00}$ was absent either in one eye or in both eyes in nine cases $(31 \%)$, and was delayed in 14 cases $(48 \%)$. Bilateral abnormalities were seen in 15 cases (32\% of all cases).

With regard to clinical stage of the illness, 14 among 17 cases $(82 \%)$ who were judged to be in exacerbation or in a chronic active (progressive) stage showed VEP abnormalities. Among 30 cases who were judged to be in remission or in a chronic stable stage, 19 cases $(63 \%)$ showed VEP abnormalities. There was no significant difference in these two groups.

With regard to the relationship with previous history of optic neuritis, P $\overline{(00}$ of pattern reversal VEP was abnormal in $93 \%$ of cases with previous history of optic neuritis versus in $40 \%$ of cases without $(p<$ $0 \cdot 002$, chi-square test) (table 3). Relationship between the peak latency of $\mathrm{P} \overline{100}$ and visual impairment of each eye at the time of recording is shown in fig 2 . When stimulating the totally blind eyes, no response was obtained. Among 14 eyes with severe visual impairment, pattern response was absent in eight and markedly delayed in the remaining six eyes. Among 29 eyes whose visual acuity was mildly reduced, 10 eyes $(34.5 \%)$ showed delayed peak latency of $P 1 \overline{00}$, and $w$-shaped response was seen in two eyes. Among 58 eyes with normal visual acuity, $\mathrm{P} \overline{100}$ peak latency was delayed in 18 eyes $(31 \%)$, and three other eyes showed $\mathrm{w}$-shaped P $\overline{\mathrm{P} 00}$ component although the initial positive peak occurred within normal limits of latency.

In the 16 eyes which showed no pattern response at all, the time interval from the last attack of optic neuritis to the time of recording ranged from 2 months to 14 years, mean $3 \cdot 0$ years $(S D=3 \cdot 2$ years $)$.

Table 3 Previous history of optic neuritis and abnormalities of $P \overline{100}$ of pattern reversal VEP

\begin{tabular}{|c|c|c|c|}
\hline & \multicolumn{2}{|c|}{ Optic neuritis } & \multirow{2}{*}{-Total } \\
\hline & Present & Absent & \\
\hline $\begin{array}{l}\text { Abnormal } \\
\text { Normal } \\
\text { Total }\end{array}$ & $\begin{array}{c}25(92.6 \%) \\
2(7.4 \%) \\
27(100 \%)\end{array}$ & $\begin{array}{r}8(40.0 \%) \\
12(60.0 \%) \\
20(100 \%)\end{array}$ & $\begin{array}{l}33(70.2 \%) \\
14(29.8 \%) \\
47(100 \%)\end{array}$ \\
\hline
\end{tabular}

$\left(X^{2}=10 \cdot 05, \mathrm{p}<0 \cdot 002\right)$

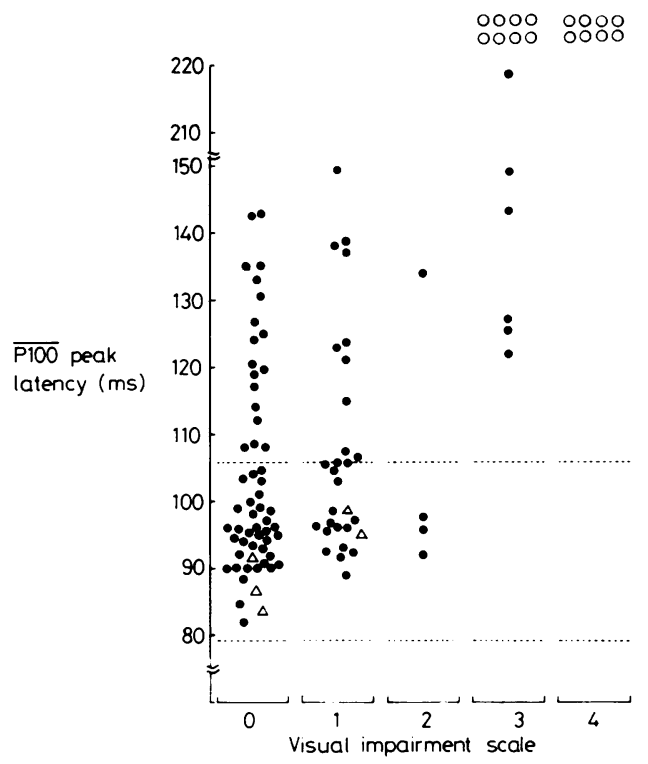

Fig 2 Peak latency of $P \overline{100}$ and visual impairment at the time of recording for each eye. Visual impairment scale: 0 , none (1.0 or above); 1 , slight $(0.5$ to 0.9$) ; 2$, moderate $(0.1$ to 0.4$)$; 3 , severe $(0.08$ or less); 4 , completely blind. Dashed lines indicate limit of normal range (mean $\pm 3 S D$ ) of $P \overline{100}$ latency, based on the control data. An open circle indicates an eye with no pattern response. A triangle; $w$-shaped $P \overline{100}$, plotted by using a latency of the initial positive peak

\section{Discussion}

A large number of studies on pattern reversal VEP in Caucasian multiple sclerosis patients have been reported from Western countries. Overall percentage of patients showing abnormal pattern responses ranged from 52 to $85 \%$, and among patients with definite multiple sclerosis, 75 to $100 \%$ of those were reported to show abnormal pattern response. ${ }^{16-3.3}$ The present study among Japanese multiple sclerosis patients, in fact the first study among orientals. demonstrated a similar percentage $(70 \%$ of overall cases and $90 \%$ of probable (clinically definite) cases).

The usefulness of pattern reversal VEP for detecting subclinical optic nerve lesions in multiple sclerosis, as originally suggested by Halliday $e t a l^{\prime}$ and later by many other investigators, was reconfirmed in the present study (fig 2). Abnormalities of pattern response were significantly more frequent among patients with previous history of optic neuritis than among those without (93\% versus $40 \%$ ) (table 3 ). This finding is also in conformity with previous reports from Western countries. ${ }^{17262931.32}$ As in studies reported by other investigators, the most 
Table 4 Percentage of patients with multiple sclerosis showing no pattern evoked response

\begin{tabular}{|c|c|c|}
\hline Reference & $\begin{array}{l}\text { Number of patients } \\
\text { or eyes tested }\end{array}$ & No response $(\%)$ \\
\hline Asselman et al 1975 (17) & 100 eyes & $2 \cdot 0$ \\
\hline Zeese $1977(23)$ & 30 cases & $13 \cdot 3$ \\
\hline Nilsson $1978(25)$ & 38 cases & $13 \cdot 2$ \\
\hline \multirow{2}{*}{$\begin{array}{c}\text { Shahrokhi et al } \\
1978(26)\end{array}$} & $\begin{array}{l}51 \text { cases of } \\
\text { optic neuritis }\end{array}$ & $13 \cdot 7$ \\
\hline & $\begin{array}{l}59 \text { eyes of } \\
\text { optic neuritis }\end{array}$ & $13 \cdot 6$ \\
\hline $\begin{array}{c}\text { Tackmann et al } \\
1979(29)\end{array}$ & 54 cases & $20 \cdot 4$ \\
\hline $\begin{array}{l}\text { Trojaborg and Petersen } \\
1979(30)\end{array}$ & 100 eyes & $3 \cdot 0$ \\
\hline Kjaer $1980(32)$ & 100 cases & $9 \cdot 0$ \\
\hline $\begin{array}{l}\text { Wilson and Keyser } \\
1980(33)\end{array}$ & 100 cases & $4 \cdot 0$ \\
\hline The present series & 47 cases & $23 \cdot 4$ \\
\hline
\end{tabular}

common abnormality was a delayed latency of the major positive peak $(\mathrm{P} \overline{\mathbf{1 0 0}})$.

The most conspicuous finding in the present study, however, was the complete absence of a pattern response either in one eye or in both eyes, which was seen in $23 \%$ of all cases or in $31 \%$ of probable multiple sclerosis cases. Although the amplitude of the pattern response has drawn much less attention as compared to the latency, several studies reported the percentage of multiple sclerosis patients showing no response (table 4). The percentage reported in the present study is greater than any of those reported from Western countries, and only the Basel series by Tackmann et $a l^{29}$ reported a percentage similar to ours. Among their 54 multiple sclerosis cases, they found no response bilaterally in five cases and unilaterally in six cases.

Halliday et $a l^{\prime}$ in their original report studied pattern reversal VEP in five patients with optic neuritis within a fortnight of the onset when a visual acuity was $6 / 60$ or less, and recorded no response in the affected eye. Subsequent recordings in four of those patients showed responses of small amplitude, although with a much delayed peak latency, when vision was still impaired.' Sixteen eyes showing no pattern response in the present study had a time interval from the last attack of optic neuritis of 2 months to 14 years (mean 3 years), indicating that none of the eyes was in the acute stage of optic neuritis. In those reports listed in table 4 , there is no information available as to whether the recording was made in acute or chronic stage of optic neuritis. Nonetheless, the present findings seem to support the previously reported clinical and pathological features of oriental multiple sclerosis that include more frequent occurrence of severe and non-remitting optic nerve involvement as compared to Caucasian cases. $^{7-15}$

Concerning the correlation between the pattern response abnormality and visual acuity, Halliday $e t$ $a l^{6}$ reported that visual acuity tested at the time of recording correlated significantly with the amplitude of the pattern response, but not with the latency. The present findings (fig 2) are in good agreement with their findings. All eyes with no pattern response had visual acuity of $0 \cdot 08$ or less, whereas delayed latency was seen regardless of the severity of visual impairment.

We are grateful to Dr AM Halliday, The National Hospital for Nervous Diseases, Queen Square, for his revision of this article.

\section{References}

' Halliday AM, McDonald WI, Mushin J. Delayed visual evoked response in optic neuritis. Lancet 1972;i: 982-5.

2 Halliday AM. Clinical applications of evoked potentials. In: Matthews WB, Glaser GH ed, Recent Advances in Clinical Neurology. Edinburgh: Churchill Livingstone, 1978;47-73.

${ }^{3}$ Halliday AM, Mushin J. The visual evoked potential in neuroophthalmology. Internat Ophthalmol Clinics 1980;20:155-83.

+ Halliday AM, Halliday E, Kriss A, McDonald WI, Mushin J. The pattern-evoked potential in compression of the anterior visual pathways. Brain 1976;99:357-74.

5 Carroll WM, Kriss A, Baraitser M, Barrett G, Halliday AM. The incidence and nature of visual pathway involvement in Friedreich's ataxia: A clinical and visual evoked potential study of 22 patients. Brain 1980;103:413-34.

6 Halliday AM, McDonald WI, Mushin J. Delayed pattern-evoked responses in optic neuritis in relation to visual acuity. Trans Ophthalmol Soc 1973;93:315-24.

7 Kuroiwa Y. Multiple sclerosis and allied demyelinating encephalomyelitis in Japan. In: Bammer HG ed, Zukunft der Neurologie. Stuttgart: Georg Thieme Verlag, 1967;70-84.

* Shibasaki H, Kuroda Y, Iwashita H, Kuroiwa Y. Clinical studies of multiple sclerosis in Japan. Multiple sclerosis starting with retrobulbar neuritis. J Neurol 1974; 208: $17-25$.

9 Kuroiwa Y, Igata A, Itahara K, Koshijima S, Tsubaki T, Toyokura Y, Shibasaki $H$. Nationwide survey of multiple sclerosis in Japan. Clinical analysis of 1,084 cases. Neurology (Minneap) 1975;25:845-51.

${ }^{10}$ Kuroiwa Y, Hung T-P, Landsborough D, Park CS Singhal BS, Soemargo S, Vejjajiva A, Shibasaki H. Multiple sclerosis in Asia. Neurology (Minneap) 1977; 27:188-92.

"Shibasaki H, Okihiro MM, Kuroiwa Y. Multiple sclerosis among Orientals and Caucasians in Hawaii: A reappraisal. Neurology (Minneap) 1978;28:113-8.

12 Kuroiwa Y, Shibasaki H. Neurological disability assessment of multiple sclerosis in Japan. Acta Neurol Scand 1981;64 (Suppl 87):66-8. 
13 Shibasaki H, McDonald WI, Kuroiwa Y. Racial modification of clinical picture of multiple sclerosis: Comparison between British and Japanese patients. $J$ Neurol Sci 1981;49:253-71.

14 Ikuta F, Koga M, Takeda S, Ohama E, Takeshita I, Ogawa $\mathrm{H}$, Wang $\mathrm{M}-\mathrm{Y}$. Comparison of multiple sclerosis pathology between 40 American and 75 Japanese autopsy cases. In: Kuroiwa Y, Kurland LT eds, Multiple Sclerosis East and West. Fukuoka: Kyushu University Press, 1982;297-306.

15 Tabira T, Tateishi J. Neuropathological features of multiple sclerosis in Japan. In: Kuroiwa Y, Kurland LT eds, Multiple Sclerosis East and West. Fukuoka: Kyushu University Press, 1982;273-95.

16 Halliday AM, McDonald WI, Mushin J. Visual evoked response in diagnosis of multiple sclerosis. $\mathrm{Br} \mathrm{Med} \mathrm{J}$ 1973;4:661-4.

17 Asselman P, Chadwick DW, Marsden CD. Visual evoked responses in the diagnosis and management of patients suspected of multiple sclerosis. Brain 1975; 98:261-82.

18 Lowitzsch K, Kuhnt U, Sakmann Ch, Maurer K, Hopf HC, Schott D, Thäter K. Visual pattern evoked responses and blink reflexes in assessment of multiple sclerosis diagnosis. A clinical study of 135 multiple sclerosis patients. $J$ Neurol 1976;213:17-32.

19 Mastaglia FL, Black JL, Collins DWK. Visual and spinal evoked potentials in diagnosis of multiple sclerosis. $\mathrm{Br}$ Med J 1976;2:732.

${ }^{20}$ Chain F, Mallecourt J, Leblanc M, Lhermitte F. Apport de l'enregistrement des potentiels évoqués visuels au diagnostic de la sclérose en plaques. Rev Neurol 1977; 133:81-8.

21 Hennerici M, Wenzel D, Freund H-J. The comparison of small-size rectangle and checkerboard stimulation for the evaluation of delayed visual evoked responses in patients suspected of multiple sclerosis. Brain 1977; 100:119-36.

22 Matthews WB, Small DG, Small M, Pountney E. Pattern reversal evoked visual potential in the diagnosis of multiple sclerosis. J Neurol Neurosurg Psychiatry 1977; 40: $1009-14$.

${ }^{23}$ Zeese JA. Pattern visual evoked responses in multiple sclerosis. Arch Neurol 1977;34:314-6.

24 Collins DWK, Black JL, Mastaglia FL. Pattern-reversal visual evoked potential. Method of analysis and results in multiple sclerosis. J Neurol Sci 1978;36:83-95.

25 Nilsson BY. Visual evoked responses in multiple sclerosis: Comparison of two methods for pattern reversal. J Neurol Neurosurg Psychiatry 1978;41: 499-504.

26 Shahrokhi F, Chiappa KH, Young RR. Pattern shift visual evoked responses. Two hundred patients with optic neuritis and/or multiple sclerosis. Arch Neurol 1978;35:65-71.

27 Bodis-Wollner I, Hendley CD, Mylin LH, Thornton J. Visual evoked potentials and the visuogram in multiple sclerosis. Ann Neurol 1979;5:40-7.

2* Clifford-Jones RE, Clarke GP, Mayles P. Crossed acoustic response combined with visual and somatosensory evoked responses in the diagnosis of multiple sclerosis. J Neurol Neurosurg Psychiatry 1979;42: 749-52.

29 Tackmann W, Strenge H, Barth R, Sojka-Raytscheff A. Diagnostic validity for different components of pattern shift visual evoked potentials in multiple sclerosis. Europ Neurol 1979;18:243-8.

30 Trojaborg W, Petersen E. Visual and somatosensory evoked cortical potentials in multiple sclerosis. $J$ Neurol Neurosurg Psychiatry 1979;42:323-30.

${ }^{31}$ Diener HCh, Scheibler H. Follow-up studies of visual potentials in multiple sclerosis evoked by checkerboard and foveal stimulation. Electroencephalogr Clin Neurophysiol 1980;49:490-6.

${ }^{32} \mathrm{Kjaer}$ M. Visual evoked potentials in normal subjects and patients with multiple sclerosis. Acta Neurol Scand 1980;62:1-13.

33 Wilson WB, Keyser RB. Comparison of the pattern and diffuse-light visual evoked responses in definite multiple sclerosis. Arch Neurol 1980;37:30-4. 